\title{
Study on the Upper Paleozoic Source Rocks in Southwestern Henan, China
}

\author{
Fengyu Sun ${ }^{1,2,3}$, Gaoshe Cao ${ }^{1,3, *}$, Zhou Xing $^{4}$ \\ ${ }^{1}$ Institute of Resources \& Environment, Henan Polytechnic University, Jiaozuo 454000, China \\ ${ }^{2}$ State Key Laboratory of Petroleum Resources and Prospecting, China University of Petroleum (Beijing), Beijing 102249, China \\ ${ }^{3}$ Collaborative Innovation Center of Coalbed Methane and Shale Gas for Central Plains Economic Region, Henan Province, Jiaozuo \\ 454000, China \\ ${ }^{4}$ College of Geosciences, China University of Petroleum (Beijing), Beijing 102249, China
}

\begin{abstract}
The Upper Paleozoic strata in Southwestern Henan have good prospects for unconventional oil and gas exploration. This paper takes the Upper Paleozoic source rocks in the Yuzhou area and the Pingdingshan area in Southwestern Henan as the research object, and tests 107 samples from the Upper Paleozoic coal rock, mudstone and carbonate rock. Combined with the sedimentary environment background, the Upper Paleozoic source rocks in Southwestern Henan are comprehensively evaluated. The results show that the Upper Paleozoic source rocks in Southwestern Henan, including coal rocks, mudstone and carbonate rocks, can be used as potential source rocks. Vertically, the source rocks are continuously distributed in the lower layer below the sandstone of Shanxi Formation. The Dazhan sandstone is only locally developed; the distribution of Upper Paleozoic source rocks in Southwestern Henan is mainly related to the Late Paleozoic transgression.
\end{abstract}

\section{Introduction}

The coal-measure strata have a good foundation for developing source rocks, and can form a "sandwich" structure with the reservoirs [1]. Coal-measure strata, tight sandstone gas and shale gas can form coal-bed methane, which are also important exploration directions $[1,2]$, and there is an relationship between the occurrence locations of these unconventional oil and gas reservoirs and potential source rocks [3]. The diverse sedimentary environment of coal-measure strata can produce different types of source rocks [3]. As a good source rocks and a reservoir of coalbed methane, previous studies have paid full attention to it [1-4]. In addition, more attention has been paid to the potential source rocks in this set of formations, but most of them are based on the geochemical indicators of a small number of oil and gas drilling samples. The lack of systematic evaluation of the source rocks in the basin affects the comprehensive understanding of the potential source rocks. The systematic evaluation of different types of source rocks and the determination of the distribution layers of favourable source rocks are important to the oil and gas exploration of coal-measure formations.

In this study, we selected samples from drilling holes in the Yuzhou area and the Pingdingshan area in Southwestern Henan to carry out a comprehensive organic geochemical analysis and evaluation. Combined with sedimentary environment analysis, the distribution of source rocks is discussed, which provides the basis for oil and gas exploration of Upper Paleozoic in Southwestern Henan.

\section{Geological background}

Southwestern Henan is in the southern part of the North China Plate. Its boundary is adjacent to the LuanchuanGushi Fault and the Qinling-Dabie Orogenic Belt in the south, the Tanlu Fault and the Yangtze Plate in the east, the Jiaozuo-Shangqiu Fault and Bohai Bay in the north. There is no conclusion on the structural attributes of the basin boundary and the western boundary. The basin mainly develops several structural units in the Kaifeng Depression, Taikang Uplift, Zhoukou Depression, Xuhuai Uplift, and Hefei Depression. The NWW near EW and NE-NNE faults control the formation and evolution of secondary structural units in the study area [5] (Figure 1).

Upper Paleozoic strata coal-measures strata from bottom to top are Benxi Formation, Taiyuan Formation, The sedimentary lithology of Shanxi Formation, Lower Shihezi Formation and Upper Shihezi Formation has typical characteristics of carbonate rock, clastic rock and coal seam mixture. Carbonate rocks are mainly developed in the Taiyuan Formation. Mudstone and coal rocks are developed in the entire Late Paleozoic coal-

*Corresponding author: caogs@hpu.edu.cn 
measure strata. The source rocks have good prospects for unconventional oil and gas exploration.

\section{Sample collection and testing}

The selected research areas in Southwestern Henan (Figure 1) reveal the Upper Paleozoic Upper Carboniferous Benxi Formation $\left(\mathrm{C}_{2} b\right)$, Lower Permian Taiyuan Formation $\left(\mathrm{P}_{1} t\right)$, Middle Permian Shanxi Formation $\left(\mathrm{P}_{2} S\right)$ and Lower Shihezi Formation. Formation $\left(\mathrm{P}_{2} x\right)$, Upper Permian Upper Shihezi Formation $\left(\mathrm{P}_{3} s\right)$ strata.

The lithology of the Benxi Formation is mainly bauxite mudstone or oolitic bauxite mudstone. The thickness of this group varies due to the influence of the paleokarst difference in the basement.

The lithology of the Taiyuan Formation is mainly composed of bioclastic or bioclastic limestone and local mineable coal seams or coal lines. The thickness of the drilling holes of this group in each area is the Yuzhou area $(72.70 \mathrm{~m})$ and the Pingdingshan area $(45.18 \mathrm{~m})$.

The lithology of the Shanxi Formation is mainly composed of sandstone, sandy mudstone, mudstone and coal seams (line). The thickness of the drilling holes in

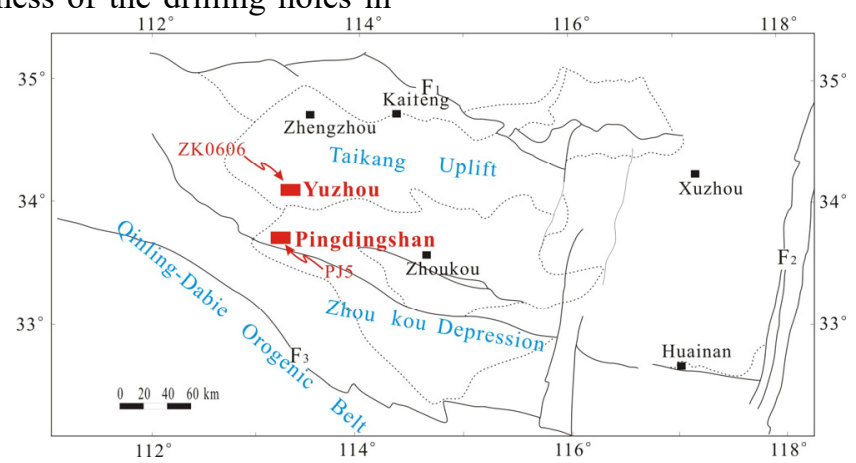

Figure 1. The structure diagram and the location of the study area (The base map is modified from Xu Hanlin et al. [5])

F1-Jiaozuo-Shangqiu Fault; F2-Tanlu Fault; F3-Luanchuan-Gushi Fault
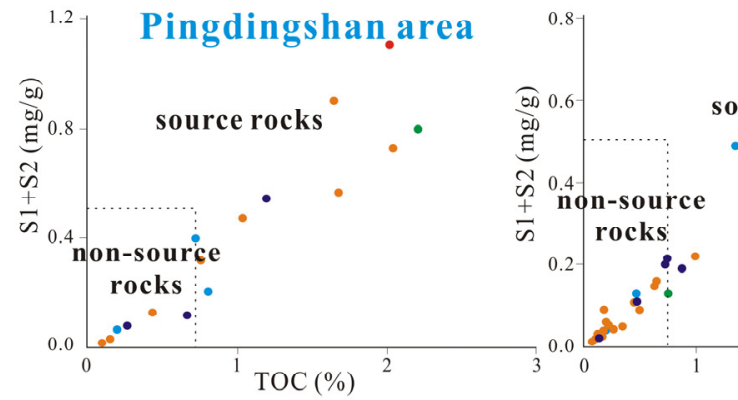

Yuzhou area

source rocks

$\longrightarrow$ mudstone of Benxi Formation

- limestone of Taiyuan Formation

- mudstone of Taiyuan Formation

- mudstone of Shanxi Formation

- mudstone of Lower Shihezi Formation

- mudstones of Upper Shihezi Formation

TO2 $2 \%)$

Figure 2. The relationship between TOC-S1+S2 in different Upper Paleozoic layers in the study area

\section{Results}

\subsection{Organic matter abundance}

Organic matter in source rocks is the material basis for the formation of oil and gas. Organic carbon content is the most commonly used and most effective indicator for evaluating source rock abundance standards, which directly affects source rock quality and hydrocarbon generation potential. The test data of TOC content in different lithological samples of the Upper Paleozoic in the study area are different [2-3].

The average total organic carbon (TOC) content of coal and rock samples is between $76.2 \%$ (2) and $77.2 \%$, and the organic matter content is high $(>40 \%)$. The abundance is no longer a restrictive factor for source rocks, so coal and rock are regarded as hydrocarbons. The source rocks are treated, and their occurrence horizons are different in the study area. The Yuzhou area is mainly found in the Shanxi Formation, followed by the Taiyuan Formation, with a controlled thickness of $>9.35 \mathrm{~m}$; the Pingdingshan area is mainly found in the 
Shanxi Formation followed by the Taiyuan Formation. In Taiyuan Formation and Xiashihezi Formation, due to the influence of the recovery factor, the downhole control thickness is only $>2.50 \mathrm{~m}$.

The average TOC content of carbonate rock samples is between $1.12 \%$ (2) and $2.73 \%$ (2), which is a good source rocks. It mainly occurs in the Taiyuan Formation, and its control thickness is $29.99 \mathrm{~m}$ in the Yuzhou area and $21.30 \mathrm{~m}$ in the Pingdingshan area.

The average TOC content of carbonaceous mudstone is between $6.56 \%$ and $14.70 \%$ (2), which is a poor-good source rock. Carbonaceous mudstone often develops near coal seams or exists in mudstone in thin layers, and its control thickness is relatively thin. Its occurrence layer and control thickness have a correlation with coal.

Mudstone has relatively low organic carbon content and differences. The average value is between $0.31 \%$ (19) and $2.88 \%$ (4). Mudstones are distributed from nonsource rocks to medium source rocks. However, most of the samples do not reach the level of source rocks, and mudstones are distributed in all layers of the Upper Paleozoic, and the control thickness is relatively large.

According to the significant positive correlation between hydrocarbon generation potential $(\mathrm{S} 1+\mathrm{S} 2)$ and TOC of Upper Paleozoic samples in different areas of Southwestern Henan (Figure 2), under the same conditions, the size of hydrocarbon generation potential also has the significance of analysing the quality and expulsion characteristics of source rocks.

\subsection{Organic matter type}

\subsubsection{Organic maceral}

The types of organic matter in each layer of the Upper Paleozoic in the study area are shown in Table 1 [3]. The organic maceral of kerogen with different lithologies are shown in Figure 3.

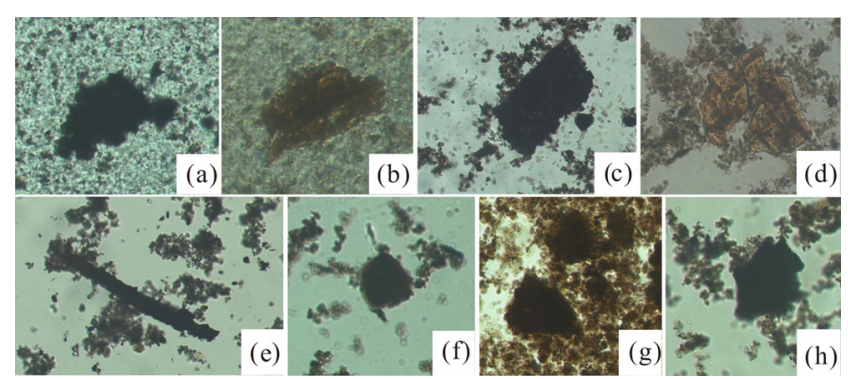

Figure 3. Organic maceral in the Paleozoic coal-measure strata in the study area

(a)- Euvitrinite in limestone (Taiyuan Formation ZK0606-1); (b)- Phyllovitrinite in limestone (Taiyuan Formation ZK06061); (c)- Euvitrinite in mudstone (Shanxi Formation ZK060611); (d)- Phyllovitrinite in mudstone (Xia Shihezi Formation ZK0606-40); (e)- Euvitrinite in limestone (Taiyuan Formation PJ5- 160); (f)-Humic amorphous body in limestone (Taiyuan Formation PJ5-160); (g)-Humic amorphous body in mudstone (Xia Shihezi Formation PJ5-63); (h)- Euvitrinite in mudstone (Shanxi Formation PJ5-131)

\subsubsection{Carbon isotopes}

The kerogen carbon isotope of Taiyuan Formation mudstone in the Yuzhou area is $-22.76 \%$, carbonate rock is $-24.10 \%$; Shanxi Formation mudstone is $-23.88 \%$; Lower Shihezi Formation mudstone is $-21.25 \%$ o(2); Upper Shihezi Formation mudstone It is $-21.41 \%$.

The kerogen carbon isotope of Taiyuan Formation mudstone in the Pingdingshan area is $-23.14 \%$ o(2), Taiyuan Formation carbonate rock is $-25.58 \%$; Shanxi Formation mudstone is $-23.80 \%$ (3), Lower Shihezi Formation mudstone is $-22.26 \%(9))$, the mudstone of the Upper Shihezi Formation is $-21.41 \%$ (3).

According to the standard of carbon isotope to distinguish the type of source rocks, the mudstone and coal rock in all strata of the Upper Paleozoic in Southwestern Henan are typeIIIkerogen, and the carbonate rock of Taiyuan Formation is type III kerogen. The points are consistent with each other.

\subsection{Thermal evolution degree of organic matter}

\subsubsection{Kerogen vitrinite reflectance (Ro)}

The limestone Ro of the Taiyuan Formation in the Yuzhou area is $2.10 \%$, and the mudstone is $2.14 \%$, indicating over-mature characteristics; the Shanxi Formation mudstone is $1.50 \%$; the Lower Shihezi Formation carbonaceous mudstone is $1.09 \%$, and the mudstone is $1.51 \%$ (3); The mudstone of the Upper Shihezi Formation is $1.46 \%$ (3), which indicates the characteristics of high maturity.

The limestone Ro of the Taiyuan Formation in the Pingdingshan area is $1.14 \%$, mudstone is $1.15 \%$ (2); Shanxi Formation mudstone is $1.15 \%$ (3), Lower Shihezi Formation mudstone is $1.07 \%$ (9); Upper Shihezi Formation mudstone is $0.59 \%$ (3) Except for the source rocks of the Upper Shihezi Formation indicated to be in the low-mature stage, the rest are in the mature stage.

\subsubsection{Peak temperature $\left(T_{\max }\right)$}

$\mathrm{T}_{\max }$ of Taiyuan Formation limestone in the Yuzhou area is $562^{\circ} \mathrm{C}$, mudstone is $567^{\circ} \mathrm{C}$; Shanxi Formation mudstone is $541^{\circ} \mathrm{C}$; Lower Shihezi Formation carbonaceous mudstone is $508^{\circ} \mathrm{C}$, mudstone is $519^{\circ} \mathrm{C}(3)$; Upper Shihezi Formation mudstone is $513{ }^{\circ} \mathrm{C}$ (3), basically indicates the characteristics of high maturity.

$\mathrm{T}_{\max }$ of Taiyuan Formation limestone in the Pingdingshan area is $473^{\circ} \mathrm{C}$, mudstone is $482^{\circ} \mathrm{C}(2)$; Shanxi Formation mudstone is $489^{\circ} \mathrm{C}(3)$, Lower Shihezi Formation mudstone is $487^{\circ} \mathrm{C}(9)$; Upper Shihezi Formation mudstone is $500^{\circ} \mathrm{C}(3)$ It also basically indicates the characteristics of high maturity.

It can be found that the $\mathrm{T}_{\max }$ index has the convergence or large fluctuations and the Ro value evaluation is different. It can be judged that it has lost its discriminative significance. Therefore, the thermal evolution degree of source rocks is mainly judged and evaluated based on the vitrinite reflectance. 
Table 1. Statistics of the organic matter type in the Upper Paleozoic layers in the study area

\begin{tabular}{|c|c|c|c|c|c|c|c|c|c|}
\hline Area & Horizon & Lithology & $\begin{array}{c}\text { Sapropelinite } \\
(\%)\end{array}$ & $\begin{array}{c}\text { Exinite } \\
(\%)\end{array}$ & $\begin{array}{c}\text { Vitrinite } \\
(\%)\end{array}$ & $\begin{array}{c}\text { Inertinite } \\
(\%)\end{array}$ & $\begin{array}{l}\text { Type } \\
\text { Index }\end{array}$ & $\delta^{13} \mathrm{C}(\%)$ & Type \\
\hline \multirow{5}{*}{$\begin{array}{c}\text { Pingding } \\
\text { shan }\end{array}$} & Upper Shihezi Formation & Mudstone & $0(3)$ & $2.7(3)$ & $95.0(3)$ & $3.5(3)$ & $-72(3)$ & $-21.41(3)$ & III \\
\hline & Lower Shihezi Formation & Mudstone & $0(9)$ & $9.7(9)$ & $87.0(9)$ & $4.8(9)$ & $-63(9)$ & $-22.26(9)$ & III \\
\hline & Shanxi Formation & Mudstone & $0(3)$ & $6.7(3)$ & $92.7(3)$ & $0.7(3)$ & $-77(3)$ & $-23.80(3)$ & III \\
\hline & \multirow{2}{*}{ Taiyuan Formation } & Mudstone & $2.5(2)$ & $0.5(2)$ & $97.0(2)$ & $0(2)$ & $-70(2)$ & $-23.14(2)$ & III \\
\hline & & Limestone & $7(1)$ & $0(1)$ & $93.0(1)$ & $0(1)$ & $-63(1)$ & $-25.58(1)$ & III \\
\hline
\end{tabular}

\section{Discussion}

\subsection{TOC difference}

According to the vertical distribution characteristics of different lithological samples from the Upper Paleozoic in different areas, it can be found that in the drilling hole ZK0606 in the Yuzhou area, samples with TOC content up to the source rock standard mainly appear in the lower part of the Shanxi Formation Dazhan sandstone, except for three layers. The grained sandstone is relatively continuous. Not only mudstone and coal rock have higher organic carbon content, but also limestone has higher organic carbon content. However, the layer above the sandstone contains more coal seams or coal lines, and the sample has 3 TOC contents. High value, which mainly develops near thin coal seams. In the drilling hole PJ5 in the Pingdingshan area, the samples that meet the source rock standards are mainly distributed in the layer below the Shanxi Formation Dazhan sandstone. They also show that they are relatively continuous except for three sandstone layers with a thickness of less than $5 \mathrm{~m}$. The Xiashihezi Formation is located in the coal seam. The nearby source rock has a higher TOC content but is larger than the control thickness in the Yuzhou area. The control thickness of the interval with TOC greater than $0.75 \%$ in the Upper Shihezi Formation is thinner.

\subsection{Significance of exploration}

Based on the systematic evaluation of Upper Paleozoic source rocks in different areas of Southwestern Henan, coal, mudstone and carbonate rocks can be regarded as potential source rocks; especially coal is the most source rock with high TOC content and hydrocarbon generation potential, followed by carbonaceous mudstone and carbonate rocks near coal seams. Vertically, the Upper Paleozoic source rocks in the north of South China are mainly distributed in the lower strata. The distribution is relatively continuous and only locally developed in the upper strata with the heterogeneity.

The study shows that the sedimentary environment of the Upper Paleozoic in Southwestern Henan is a complete transgressive regressive cycle [1-2]. The transition point of the complete cycle is near the maximum flooding surface, which has been at a relatively stable base level for a long time, and the source rock development conditions are superior.

\section{Conclusion}

The Upper Paleozoic source rocks in Southwestern Henan, including coal rocks, mudstone and carbonate rocks, can be used as potential source rocks.

The Upper Paleozoic source rocks in Southwestern Henan are vertically continuously distributed in the lower strata below the Dazhan sandstone of the Shanxi Formation; its distribution is mainly related to the transgression of the Late Paleozoic transgression.

\section{Acknowledgments}

This research was funded by Investigation and Appraisal of Oil and Gas Strategic Areas throughout China (Grant No.1211302108023-2), the Doctoral Foundation of Henan Polytechnic University (Grant No.B2021-77) and State Key Laboratory of Petroleum Resources and Prospecting, China University of Petroleum, Beijing (Grant No. PRP/open-1809). The authors are very grateful to the graduated students, Xing Zhou, Fang Bangbang, Yu Shuangjie, etc..

\section{References}

1. Sun, F.Y., Cao, G.S., Xing, Z., Yu, S.J.\& Fang, B.B. (2021) Characteristics and evaluation of the Upper Paleozoic source rocks in the Southern North China Basin. Open Geosci. 13(1): 294-309.

2. Xing Z., Cao G.S., Bi J.H., Zhou X.G., Zhang J.D. (2018) The evaluation of Upper Paleozoic hydrocarbon source rocks of ZK0606 inYuzhou region at southern North China Basin. Nat Gas Geosci.29(4):518-28.

3. Cao G.S., Xing Z., Bi J.H., Zhang J.D. (2018) Evaluation of hydrocarbonsource rocks of PJ5 in Pingdingshan, southern North Chinabasin. J Henan Polytech Univ (Nat Sci). 37(1):37-45 (in Chinese with English abstract).

4. Sun F.Y. Study on provenance and aluminum enrichment of the Benxi Formation in the southeastern part of North China Block. Doctoral dissertation of Henan Polytechnic University, 2019.

5. Xu H.L.,Zhao Z.J., Yang Y.N., Tang Z.W. (2003) Structural pattern and structural style of the Southern North China Basin. Acta Geosci. Sin. 24(1):27-33(in Chinese with English abstract). 